\title{
Era uma vez uma teoria do desenvolvimento econômico: entre contos e crônicas
}

\author{
Emily Santos MOTA ${ }^{1}$
}

\begin{abstract}
RESUMO
O presente artigo tem como objetivo analisar como as concepções sobre uma teoria do desenvolvimento econômico é bem heterogênea na seara das escolas ortodoxa e heterodoxa. Enquanto no primeiro grupo as definições estão conectadas com os aspectos quantitativos, modelísticos e matematizados, a segunda escola não abstrai de sua teoria os aspectos quantitativos, mas ao contrário da primeira, acrescenta o caráter qualitativo e histórico nas suas análises. O Desta forma, foi utilizada uma linguagem metafórica para debater e criticar as definições utilizadas por cada grupo. Para tal análise foi empregada a pesquisa bibliográfica já tinha como objetivo analisar as diversas definições acerca do problema anteriormente apresentado. Conclui-se o referido artigo afirmando que a teoria do desenvolvimento econômico tem uma natureza complexa e subjetiva, em que de um lado tem-se um grupo amparado na simplificação do modelo de crescimento econômico em inúmeros aspectos, dentre os quais vale mencionar a diferença conceitual inexistente entre crescimento e desenvolvimento, a racionalidade do indivíduo, e a problemática da distribuição de renda. E do outro lado tem-se um grupo que se ampara na realidade subjetiva presente no processo de desenvolvimento, amplificando aquilo que está simplificado dentro de modelos limitados que não abordam a complexidade econômica.
\end{abstract}

Palavras-chave: Desenvolvimento econômico, Teoria e Escolas de pensamento

\section{Once upon a time there was a theory of economic development: among tales and chronicles} \begin{abstract}
This article aims to analyze how the conceptions about a theory of economic development is very heterogeneous in the area of the orthodox and heterodox schools. Whereas in the first group the definitions are connected with the quantitative, model and mathematical aspects, the second school does not abstract from its theory the quantitative aspects, but unlike the first, it adds the qualitative and historical character in its analyzes. In this way, a metaphorical language was used to discuss and critique the definitions used by each group. For this analysis was used the bibliographic research already had as objective to analyze the diverse definitions about the problem previously presented. The article concludes by stating that the theory of economic development has a complex and subjective nature, in which on the one hand there is a group supported by the simplification of the model of economic growth in innumerable aspects, among which it is worth mentioning the conceptual difference growth and development, the rationality of the individual, and the problem of income distribution. And on the other side there is a group that relies on the subjective reality present in the development process, amplifying what is simplified within limited models that do not address the economic complexity.
\end{abstract}

Keywords: Economic development, Theory and Schools of thought

\section{INTRODUÇÃO}

O presente artigo tem como objetivo analisar como as concepções sobre uma teoria do desenvolvimento econômico é bem heterogênea na seara das escolas ortodoxa e heterodoxa. Enquanto no primeiro grupo as definições estão conectadas com os aspectos quantitativos, modelísticos e matematizados, a segunda escola não abstrai de sua teoria os aspectos quantitativos, mas ao contrário da

\footnotetext{
${ }^{1}$ Bacharela em Ciências Econômicas. Mestranda em Economia e Desenvolvimento. Universidade Federal de Santa Maria (UFSM). Email: emilystsmota@gmail.com
} 
primeira, acrescenta o caráter qualitativo e histórico nas suas análises. Vale ressaltar que dentro de cada escola existem linhas de pensamentos que divergem, por isso, o presente trabalho não pretende generalizar a análise para todas as linhas de pensamento de cada escola.

Desta forma, a presente pesquisa irá utilizar-se de uma linguagem metafórica para debater e criticara temática. A primeira crítica feita se encontra no próprio título: "Era uma vez uma teoria do desenvolvimento econômico: entre contos e crônicas". A começar coma expressão "era uma vez", que nos traz a lembrança daquelas diversas histórias contadas quando ainda éramos crianças, as famosas fábulas, que tinham nos seus enredos a presença de animais/criaturas com características antropomórficas, ou seja, ideias fantasiosas e fictícias. Assim, a expressão "Era uma vez" nos faz questionar até que ponto as teorias sobre desenvolvimento econômico convergem com a realidade ou têm se mantido no mundo ficcional e fantasioso.

A ideia de contos e crônicas delimita melhor a crítica feita pelo presente artigo. A partir das características literárias dos dois gêneros é feita a conexão com os pensamentos das duas escolas já mencionadas anteriormente. A ideia de conto foi atrelada a escola ortodoxa, mais precisamente a linha de pensamento neoclássica, devido ao próprio entendimento de desenvolvimento como sinônimo de crescimento econômico e de sua análise pautar-se em modelos quantitativos, abstraindo as concepções históricas e qualitativas. Já a ideia de crônica foi vinculada a escola heterodoxa, na linha estruturalista, que entende o desenvolvimento a partir dos seus quantitativos como qualitativos.

A proposta parece ser bem mais específica do que consta no primeiro parágrafo. A ideia é contrastar neoclássicos e estruturalistas? Em que contexto?

À vista dessa problemática, o presente artigo está dividido em duas partes, além dessa introdução e das considerações finais. Na primeira parte, as discussões estão vinculadas às percepções da corrente neoclássica acerca de uma teoria do crescimento/desenvolvimento econômico. Já na segunda parte, serão apresentadas as concepções pertinentes à visão heterodoxa sobre a construção de uma teoria do desenvolvimento econômico, contrapondo-se aos ideais neoclássicos. No cerne da teoria desenvolvimentista se encontram as estruturas sociais como ideia que vai além das concepções naturais, lógicas e quantitativas trabalhadas pela linha neoclássica.

\section{UM CONTO ORTODOXO SOBRE A TEORIA DO DESENVOLVIMENTO ECONÔMICO}

As constatações ortodoxas acerca do desenvolvimento econômico se restringem ao plano do crescimento econômico, bem como aos modelos para explicar e projetar tal 
crescimento. Assim, essa abordagem ganha um caráter de conto no presente artigo, já que a natureza literária do conto se encontra na simplificação das histórias, que muitas vezes são ficcionais, no final súbito, no objetivo único, entres outras características. Cabe mencionar, ainda, que o presente trabalho não pretende generalizar a ideia de conto para todas as teorias ortodoxas do crescimento/desenvolvimento econômico, mas criticar como parte dessas teorias desapegam-se do mundo real para formular modelo impecáveis que explicam uma realidade paralela a que se encontram.

A corrente neoclássica, participante da escola ortodoxa, enxerga que, de acordo com Siedenberg (2006), o desenvolvimento e crescimento econômico como sinônimos. Essa corrente entende o crescimento econômico como um processo de transformações de particularidade quantitativa. Segundo o autor, os neoclássicos definem crescimento econômico como o aumento da capacidade produtiva e, também, da produção de uma economia em demarcado período de tempo. Habitualmente, o crescimento econômico é estimado pela variação do Produto Nacional Bruto (PNB) ou do Produto Interno Bruto (PIB).

Nali de Jesus Souza (2005) ressalta essa particularidade quantitativa, afirmando que o conceito de crescimento econômico neoclássico é baseado em equações e em um conjunto de pressupostos, tais como a concorrência perfeita e o pleno emprego em todos os mercados. Consistindo, ainda, em uma economia fechada e sem a presença do governo, capaz de produzir um bem com apenas três fatores, quais sejam: capital fixo, trabalho e terra. Além de acreditarem que os fatores de produção são homogêneos, divisíveis e imperfeitamente substituíveis entre si.

Furtado (1967) elucida a visão neoclássica sobre a teoria do desenvolvimento econômico afirmando que eles seguiam a seguinte formula:

O aumento da produtividade do trabalho (que se reflete na elevação do salário real) é consequência da acumulação de capital, a qual, por sua vez, está na dependência da taxa antecipada de remuneração dos novos capitais e do preço de oferta da poupança. A acumulação de capital, provocando um aumento nos salários reais, tenderia a incrementar a participação dos assalariados no produto e, por tanto, a reduzir a taxa média de rentabilidade do capital. Ora, diminuindo o preço de procura do capital, haveria desestímulo à poupança e consequentemente redução do nível de acumulação de capital. Retrocedemos, desta forma a teoria da estagnação. A rigor, as ideias de lucro, acumulação, desenvolvimento, não cabem no modelo neoclássico senão como consequência de um afastamento da posição de equilíbrio. Nesta, a remuneração do capital tem que ser igual em todas as suas aplicações, correspondendo à taxa de juros. Na medida em que existiam lucros, vale dizer, remuneração para o capital, em determinado setor, superior a média, cabe deduzir que não foi alcançada a distribuição ótima dos recursos produtivos, pois seria possível aumentar a produtividade de um fator deslocando-o de um para outro setor (FURTADO, 1967, p. 38).

Sawaya (2015) complementa o que foi dito por Furtado, afirmando que o pensamento neoclássico baseia-se no aspecto de natureza humana materializada em um padrão ideal de 
homem utilitarista, que determina seu comportamento como um agente que realiza escolhas racionais na presença de uma escassez que seria estrutural e inevitável, ante a suposição de equilíbrio geral entre oferta e demanda. Desta forma, a teoria da estagnação proferida por Furtado (1967), anteriormente, constitui a condição necessária à utilização mais racional dos recursos. Como consequência a economia tenderia ao desenvolvimento.

Um exemplo bastante conhecido de um modelo de crescimento econômico neoclássico é o modelo de Solow que foi construído em torno de duas equações. A primeira foi uma equação sobre a função produção que tem como finalidade descrever de qual forma capital e trabalho se combinam para gerar uma unidade de mercadoria. Segundo Solow (1956, p.66),"Output is produced with the help of two factors of production, capital and labor, whose rate of input is $L(t)$. Technological possibilities are represented by a production function, $Y=F(K, L)$ '”. Desta maneira, Solow afirma que a função de produção apresenta uma tendência a reduzir a inclinação ao longo da curva à medida que aumenta a quantidade de capital por trabalhador, pois a função de produção assume rendimentos marginais decrescentes de escala.

Em síntese, todas as variáveis da função de produção devem ser divididas pelo tamanho da força de trabalho, $L$. Em seguida tem-se: $Y / L=F(L / K, 1)$, ou $y=f(k, 1)$. Ou melhor, a produção por trabalhador é função do capital por trabalhador, com isso a uma simplificação para ilustrar o papel do capital no crescimento econômico.

A segunda equação é uma função de acumulação de capital, que, como próprio nome já identifica, tem o objetivo analisar a acumulação do capital no longo prazo. Nesta equação, Solow afirma que a variação anual do estoque de capital irá depender do investimento que este despenderá da função produção, visto que, se não produzir não terá como poupar, logo, não terá como investir. Solow não esqueceu de atribuir a esta função a depreciação da função de capital e o retorno do capital, que tem ligação intima com a taxa de crescimento da população, uma vez que esta última afeta a disponibilidade de mão-de-obra.

A partir deste ponto a seção centra apenas na crítica. E onde está a teoria ortodoxa que deveria ser apresentada nessa seção?

Outro ponto importante é que economistas neoclássicos entendem que o desenvolvimento econômico existiu em todos os períodos da história da sociedade, sendo resultado, tão somente, da acumulação de capital, ou seja, do crescimento do produto global bruto. Gelcer (2012) critica tal postura:

Ao se levar em consideração somente o produto global bruto da nação em relação ao número de habitantes, mas sem a ponderação de outros fatores, a ideia de crescimento econômico traz uma noção simplificadora da realidade, colocando todos os países dentro da mesma 
perspectiva. Apesar de a noção do crescimento ser um importante instrumento de análise do desenvolvimento econômico, vista de forma isolada, traz uma ideia opaca e muito simplificada do real grau de desenvolvimento de determinado país (GELCER, 2012, p.14).

Analisar o desenvolvimento econômico tão somente a partir do aumento do produto interno, como mencionado anteriormente por Gelcer, é simplificar a realidade. Furtado (1967), define que o desenvolvimento compreende a ideia de crescimento, porém, superando-a. Sendo assim, o desenvolvimento refere-se ao crescimento de um conjunto de estruturas complexas, sendo tal complexidade não somente uma questão de nível tecnológico, mas sim, uma tradução da diversidade das formas sociais e econômicas engendrada pela divisão do trabalho social.

Nesse sentido, Furtado admite que o crescimento é parte de um processo de desenvolvimento, mas este último repercute para o conjunto da sociedade:

O crescimento econômico é o aumento da produção, isto é, do fluxo de renda, ao nível de um subconjunto econômico especializado, e que o desenvolvimento é o mesmo fenômeno quando observado do ponto de vista de suas repercussões no conjunto econômico de estrutura complexa que inclui a anterior. Já observamos que o crescimento de um subconjunto pode apresentar-se como simples transferência de recurso em detrimento de outros setores. É o caso, por exemplo, de um país cujas terras já estão todas ocupadas e que desenvolve um setor agrícola para exportação. A modificação na composição da produção agrícola - em benefício do setor de mais alta produtividade econômica - terá repercussões nas taxas de lucros e poupança, na distribuição da renda, na composição da demanda global e, possivelmente, na taxa de inversão. Uma vez concretizadas, essas repercussões se traduzem em modificações na estrutura. Desta forma, as modificações na estrutura produtiva ao nível do conjunto complexo acarretam outras modificações estruturais na forma como se distribui e utiliza a renda. O conjunto dessas modificações estruturais constitui o processo de desenvolvimento (FURTADO, 1967, p. 74).

Para Gelcer (2012), o conceito de crescimento econômico utilizado pelos neoclássicos como índice de análise do desenvolvimento econômico, deve-se ao fato de ser relativamente fácil e de simples manipulação. Ademais, a utilização do índice de crescimento econômico atrelado ao conceito de desenvolvimento econômico, baseado nos pressupostos dos economistas neoclássicos, até então, traz a ideia de que a riqueza crescente se distribuiria entre a população automaticamente, conduzindo a melhoria da qualidade de vida de uma forma global da população. Isto é, bastaria a existência do acúmulo de capital para que todos pudessem usufruir dessa riqueza como um todo.

Apesar disso, Gelcer (2012) notabiliza que mesmo que a economia de um país ascenda a taxas relativamente altas, outros problemas econômicos surgirão, e, não necessariamente estarão subordinados ao aumento de riqueza, podendo acontecer concomitantemente. $\mathrm{O}$ aumento do desemprego, a transferência do excedente de riqueza e o desenvolvimento tecnológico para outros países, o aumento da concentração de renda, a baixa dos salários pagos, são exemplos desses problemas, que poderão implicar, consequentemente, na diminuição do consumo do mercado interno e do atraso no desenvolvimento tecnológico. 
Bresser-Pereira (2006) afirma que Schumpeter foi o primeiro economista a constatar a diferença entre crescimento e desenvolvimento econômico, afirmando que o desenvolvimento econômico é o resultado de transformações estruturais do sistema econômico, que somente o aumento da renda per capita não assegura. Ainda segundo Bresser-Pereira, Schumpeter distinguiu esse processo para ressaltar a ausência de lucro econômico no fluxo circular, em que na pior das hipóteses ocorreria crescimento, e para expor a importância da inovação no legítimo processo de desenvolvimento econômico.

Bresser-Pereira (2006) criticou esse posicionamento de Shumpeter afirmando que o economista usou para se desvincular parcialmente do pensamento neoclássico, afirmando que tal distinção era meramente teórica, não constituindo sentido do ponto de vista histórico. E para justificar tal crítica, o autor corroborou com a veracidade de que existem circunstancias na quais o crescimento de renda per capita não acarreta essas transformações e não caracteriza desenvolvimento econômico. Ele exemplifica essa afirmação através do caso dos países cuja renda per capita aumenta devido à exploração de um determinado recurso natural. Excluindo, todavia, a existência de transformações estruturais na economia, porque a produção do bem ocorre em regime de enclave, em que o progresso técnico limita-se quase que exclusivamente àquele setor.

De acordo com Bresser-Pereira (2006), o desenvolvimento econômico pode ser pensando a partir de dois pontos de vista. O primeiro, do ponto de vista da oferta, pressupondo que o crescimento da produtividade de um país provém, a longo prazo, da acumulação do capital humano. Sendo assim, da melhoria dos níveis de saúde, educação e competência técnica da população, além da acumulação de capital físico a ser operado por essa mão-de-obra cada vez mais qualificada. Capital este que admite expandir ou multiplicar a produção por trabalhador. O segundo, do ponto de vista da demanda, considerando que o capital humano precisa de emprego para se transformar em produção. Logo, a demanda é garantida, basicamente, pelo investimento ou acumulação de capital, que, por conseguinte, atua tanto do lado da oferta quando da demanda, e pelo emprego que essa acumulação cria.

Dessa forma, a existência de investimento está atrelada a uma taxa de lucro satisfatória para os empresários, e uma taxa de juros moderada, de maneira que a diferença entre as mencionadas taxas seja, também, satisfatória. Essa taxa de lucro satisfatória advém da existência de economias externas a meio-termo de diversos investimentos que estão ocorrendo e de uma taxa de câmbio competitiva que torne rentável o investimento e, deste modo, o 
emprego dos recursos humanos existentes na produção de bens comercializáveis mundialmente (BRESSER-PEREIRA, 2006).

Voltar à análise da economia de um país somente para o preceito do crescimento econômico é, como afirmou Gelcer (2012), deixar de levar em consideração o tipo de crescimento ao qual estaria se aludindo, para quem, com qual finalidade e em quais categorias. Em determinadas situações, a existência de crescimento econômico sem a consideração de outros fatores, pode mascarar uma situação de empobrecimento, por exemplo, quando há excessiva concentração de renda, desmantelamento do mercado consumidor interno, intensificação na produção, comercialização e exportação de matérias-primas em detrimento de produtos manufaturados, destruição dos recursos naturais não renováveis.

Nesse sentido, para este autor, crescimento, por si só, não vai corresponder a desenvolvimento, contudo, não vai existir desenvolvimento econômico sem um determinado nível de crescimento do produto:

Nos países em desenvolvimento, torna-se ainda mais perigoso admitir que o crescimento do produto global bruto leve, automaticamente, o país ao desenvolvimento econômico. Principalmente quando se trata da economia destes países em desenvolvimento, se torna ainda mais importante a caracterização do crescimento econômico como mero acúmulo de capital em que não há a transformação das estruturais sociais, produtivas e políticas do país. Tomar em consideração o desenvolvimento é fazer compreender o risco do crescimento sem desenvolvimento. Se acreditássemos que o simples acúmulo de capital levaria estes países subdesenvolvidos a superarem esta condição, chegando ao nível econômico dos países desenvolvidos, correríamos o sério risco de manter a nossa situação de dependência e de subdesenvolvimento sem ao menos saber o porquê e sem meios e bases teóricas para formular políticas desenvolvimentistas com a finalidade de alteração destas estruturas (GELCER, 2012, p.15).

Bresser-Pereira (2006) afirmar que não existe desenvolvimento econômico sem lucro e investimento. Ocasionalmente, pode acontecer sem um determinado grau de desigualdade e de consumo de luxo, porém, com exceção a períodos curtos, não é praticável guiar a produção tão somente para a produção dos bens de capital e bens de consumo sofisticado e, em contrapartida, deixar os trabalhadores reduzidos à sobrevivência. Notavelmente, o que se observa, em um dado período histórico, é o crescimento dos salários e da demanda de bens de consumo pelos assalariados na proporção do aumento da renda per capita.

Em casos como esses, subentende-se o desenvolvimento econômico como um processo de aumento da produtividade e dos rendimentos do fator trabalho. Implicando, entre outros aspectos, em elevação quantitativa e qualitativa dos níveis de educação, saúde e competência técnica dos trabalhadores, e da crescente migração da força de trabalho dos setores menos desenvolvidos para setores com maior grau tecnológico, que pagam salários superiores. 
Gelcer (2012) corrobora com a ideia de que é necessário conceber o entendimento de desenvolvimento econômico de forma mais vasta e absoluta do que simplesmente a noção de aumento do produto global bruto. Logo, a concepção de desenvolvimento deve levar em consideração uma diversificada gama de fatores, como por exemplo, a distribuição da renda, o desenvolvimento tecnológico e industrial, a ocupação das terras produtivas, a utilização dos recursos naturais não renováveis de maneira não comprometedora, o crescimento do mercado interno e não somente da exportação.

\section{UMA CRÔNICA HETERODOXA SOBRE A TEORIA DO DESENVOLVIMENTO ECONÔMICO}

A escola heterodoxa traz em suas linhas de pensamento um conceito de desenvolvimento econômico que não se restringem ao plano do crescimento econômico e foge da simplificação dos modelos para explicar e projetar tal crescimento. Assim, essa abordagem ganha um caráter de crônica, já que uma característica importante da crônica se encontra na crítica, que segundo Coutinho (1992) traz uma análise fundamentada em fatos e trata de assuntos do cotidiano, ou seja, lida com a realidade, com a complexidade dos fenômenos sociais.

Desta maneira, a crônica pode ser comparada metaforicamente a essa nova perspectiva heterodoxa que considera a historicidade, e analisa o indivíduo como ser social e subjetivo. É de grande importância destacar que a ideia de crônica não será generalizada para todas as linhas de pensamento da escola heterodoxas, uma vez que nem sempre esse gênero consegue abordar completamente a realidade em suas análises.

Dentro da esfera do desenvolvimento, a teoria neoclássica participa de forma expressiva em discussões de diversos campos da economia, trazendo, inclusive, uma abordagem determinista de fenômenos e processos. Segundo Fonseca (2004), essa teoria trata os diversos seguimentos econômicos como um conjunto de leis objetivas e universais, que independem da vontade humana como determinante decisório, e tendem, em sentido amplo, ao pleno emprego dos recursos.

Essa objetividade que afasta o fator humano dos processos e inutiliza os governos como elaboradores de políticas, ao atribuir a uma força invisível a capacidade de alocar plenamente os recursos econômicos, passou a ser criticada pela vertente heterodoxa, e por ela considerada simplista em alguns aspectos e com pouca aplicabilidade real. 
Um dos objetos presentes em discussões que são fontes de críticas à teoria neoclássica é a distribuição de renda dentro do processo de desenvolvimento econômico. Segundo Fonseca (2004), na visão ricardiana, mas não restrito a ela, a distribuição e desenvolvimento acontecem dentro de um processo único, possível de ser tratado como o primeiro sendo consequência do segundo respectivamente, e segue ainda leis universais (escassez de terras férteis justificando a má distribuição, salário de subsistência, e lucros provenientes da sobra).

Segundo a "lei férrea dos salários", a evolução do processo distributivo ocorre a partir do aumento da produtividade, uma vez que a renda nacional cresce, e com ela a maior participação dos trabalhadores em sua divisão, ou seja, a teoria traz à tona a ideia de que é preciso crescer para dividir. A teoria aborda o processo "desenvolver para então distribuir", como uma ação natural do próprio mercado, que sozinho, sem nenhuma participação do Estado como elaborador de políticas de distribuição de renda, consegue tal resultado naturalmente.

Dentro da análise da crônica, tratar a distribuição de renda como um fenômeno natural que dispensa qualquer política engajada em tal objetivo, configura-se como uma fuga da realidade, uma vez que se não há a necessidade de melhoria dos indicadores sociais ou buscar políticas que as proporcione, a realidade contada pela crônica passa a ser simplificada por um conto econômico da naturalização.

A crítica, no entanto, esclarece que nem toda teoria está errada acerca da produtividade anteceder o desenvolvimento, uma vez que ela é condição necessária para a melhoria dos indicadores sociais, mas não condição suficiente.

Na perspectiva marxista a estrutura econômica pode ser entendida como a forma que a sociedade produz e distribui os bens e serviços que lhe são necessários. Marx (1859) definiu a estrutura econômica como sendo o elemento fundamental sobre o qual se edificam as demais dimensões da sociedade, como a política, poder judiciário, a cultura, a religião e, inclusive, a ciência. E os elementos fundamentais da estrutura são as relações sociais de produção e as forças produtivas (LEFEBVRE, 2009). Nessa perspectiva analítica, a vida social é, em última instância, determinada pela sua estrutura econômica. De modo que, o desenvolvimento de uma sociedade está fortemente condicionado pelo desenvolvimento de sua economia.

Bresser-Pereira (2006) constata que na medida em que o desenvolvimento implica mudanças na estrutura, na cultura e nas instituições da sociedade, não é possível investigá-lo unicamente do ponto de vista econômico, dada a relação com as transformações no nível mais sólido da sociedade, que é o estrutural. Como a tecnologia é um fator dinâmico por excelência, os moldes da propriedade estão sempre evoluindo e as classes e demais grupos sociais estão 
sempre em um contínuo processo de mudança. É verdade que o desenvolvimento está relacionado a mudanças ideológicas que espelhamos interesses dos diversos grupos sociais em conflito e cooperação. E, também, a um duradouro processo de mudança das instituições, que, na maioria das vezes, adiantam as transformações nos outros níveis, podendo convir de obstáculos ou facilmente buscar dar conta das mudanças estruturais e culturais já sucedidas.

Gelcer (2012) concorda com Bresser-Pereira no tocante às estruturas, afirmando que para os países subdesenvolvidos, o desenvolvimento econômico deve ser percebido, a priori, como a transformação das estruturas sociais, econômicas e políticas, as quais, nestes países, são atrasadas. A modificação da estrutura do país deve possibilitar que se mantenha um contínuo aumento da produtividade, acúmulo de riquezas e a melhora na qualidade de vida das pessoas. A magnitude de se entender o desenvolvimento com este sentido de transformação das estruturas, depreende-se na necessidade de se romper com determinadas raízes históricas, que eventualmente poderiam impedir o desenvolvimento de determinada localidade.

A respeito da divergência na associação de crescimento a desenvolvimento, Gelcer destaque que

É bem verdade que não existe desenvolvimento sem crescimento econômico. Já houve economistas europeus que sustentaram a possibilidade de existir desenvolvimento sem crescimento econômico, baseados na ideia de que a partir de determinado nível de desenvolvimento econômico, mesmo sem crescimento posterior, seria possível proceder à distribuição do produto e do rendimento à população, ou por meio da elevação dos salários, ou por meio de transferências sociais, permanecendo tudo igual em relação ao resto - manutenção das mesmas taxas de lucro e de preços. Contudo, tais teorias não se sustentaram, uma vez que em um cenário em que não há crescimento econômico, o aumento da parte relativa aos salários, implica, necessariamente, a diminuição do lucro, o que faz diminuir na mesma proporção às taxas de investimento, e, por isso, um retrocesso no desenvolvimento. Assim, a noção de desenvolvimento econômico deve compreender a ideia de crescimento superando-a (GELCER, 2012, p.16)

Furtado (1967) conclui que a teoria do desenvolvimento se trata de analisar, dentro de uma perspectiva macroeconômica, as razões e o motivo do aumento da produtividade do fator trabalho e seus efeitos na organização da produção e na maneira como se dissemina e utiliza o produto social. Deste modo, Furtado (1967) aponta dois caminhos de análise, o primeiro, em que há existência de formulações abstratas correspondentes a análise do mecanismo do processo de crescimento econômico, o que, de certa forma, exige a elaboração de modelos simplificado do sistema econômico vigente, portanto, baseados em relações estáveis entre variáveis quantitativas de grande importância.

O segundo caminho é a análise do plano histórico. Nesse caso, Furtado (1967) aponta a necessidade de um estudo crítico em conflito com a realidade, dadas as categorias definidas pela análise abstrata. Sendo assim, não é suficiente apenas a construção de um modelo abstrato e a interpretação do 
seu funcionamento, mas sim, a verificação da eficácia explicativa desse modelo em comparação com uma realidade histórica. Apenas esse tipo de verificação indicará os limites decorrentes do nível de abstração em que foi executado o modelo e, caso necessário, sugerir alterações a serem introduzidas para tornar válido da perspectiva de uma realidade social.

Portanto, o desenvolvimento econômico deve ser entendido, em uma perspectiva ampla e múltipla que inclui tanto o crescimento do produto, quanto a análise histórica das mudanças estruturais. Neste trabalho, adota-se a abordagem Furtadiana desse fenômeno, que entende que desenvolver economicamente implica também em transformações socioeconômicas que minimizem as desigualdades sociais, por isso sua análise não deve se basear apenas na mensuração da renda.

Nesse aspecto, é possível relatar, também, dentro da teoria clássica, pontos de realidade e análises do cotidiano, proporcionando à crítica, dentro da narrativa crônica, a oportunidade de contrapor questões fictícias que se enquadram no quesito conto, e concordar, dentro da ortodoxia, com fatores que se engajam na realidade econômica e social.

\section{CONSIDERAÇÕES FINAIS}

Diante daquilo que se objetivou como análise, conclui-se então, que o conto neoclássico se encontra amparado na simplificação do modelo de crescimento econômico em inúmeros aspectos, dentre os quais se pode citar a diferença conceitual inexistente entre crescimento e desenvolvimento, a racionalidade do indivíduo, e a problemática da distribuição de renda.

Como uma crítica a esse conto econômico, a heterodoxia surge como uma crônica social ampliando as perspectivas neoclássicas quanto à realidade subjetiva presente no processo de desenvolvimento, no entanto, esta não procura uma discussão que exclui a teoria neoclássica, apenas amplifica aquilo que está simplificado dentro de modelos limitados que não abordam a complexidade econômica.

O primeiro ponto anteriormente citado define desenvolvimento e crescimento como uma transformação do processo produtivo a níveis quantitativos em desapego às melhorias dos indicadores sociais. A heterodoxia esclarece, em uma forma de ir além da simplificação, que o desenvolvimento se aproxima do crescimento, mas que vai além dele, ou seja, o crescimento é condição necessária para se atingir o desenvolvimento, mas não condição suficiente, pois para a análise da crônica realista, transformações nas estruturas sociais e políticas, assim como mudanças nas qualidades de vida da população são necessárias para que se atinja o crescimento econômico. 
O segundo ponto a ser criticado, teoriza que o indivíduo toma as suas decisões baseadas exclusivamente em decisões racionais, deixando de lado os demais aspectos que o compõe, tratando, assim, de indivíduos completamente maximizadores da utilidade. A crônica heterodoxa busca lembrar que o indivíduo não é irracional, no entanto não tem suas decisões determinadas por cálculos visando maximizar sua utilidade exclusivamente, uma vez que a individualidade é composta por fatores históricos e também influenciada por fatores sociais. O indivíduo é, então, subjetivo perante uma sociedade heterogênea diante da tomada de decisões.

E por último, a distribuição de renda entra em discussão na abordagem do conto neoclássico como um processo natural, ou seja, quando a economia crescer haverá uma melhor distribuição, consequentemente. A heterodoxia esclarece que esse processo necessita do fator humano no processo decisório, e acreditar que não é preciso elaborar qualquer política que tenha como finalidade a distribuição de renda como objetivo final, foge completamente da realidade.

\section{REFERÊNCIAS}

BRESSER-PEREIRA, L. C. Do Estado Patrimonial ao Gerencial. In:PINHEIRO, WILHEIM, SACHS (orgs.), Brasil: Um Século de Transformações. São Paulo: Cia. das Letras, 2001.

BRESSER-PEREIRA, L. C. O conceito histórico de desenvolvimento econômico. São Paulo. FGV-EESP, 2006. Disponível em: http://www.bresserpereira.org.br/papers/2006/06.7conceitohistoricodesenvolvimento.pdf. Acesso em: 23 de fev. de 2016.

COUTINHO, A. Introdução à literatura no Brasil. Rio de Janeiro: Bertrand Brasil S.A, 1988.

FONSECA, P. C. D. Desenvolvimento Econômico e Distribuição de Renda. Uma Nova Relação Entre Estado, Sociedade e Economia no Brasil. Santa Cruz do Sul: EDUNISC, Santa Cruz do Sul, v. 1, n. 1, p.269-292, nov. 2004.

FURTADO, C.. Dialética do desenvolvimento. Rio de Janeiro: Fundo de Cultura, 1964.

FURTADO, C. Formação econômica do Brasil. 34. ed. São Paulo: Companhia das Letras, 2007.

FURTADO, C. Teoria e Política do Desenvolvimento Econômico. São Paulo. Companhia Editorial Nacional. 1967.

GELCER, D. M.A Teoria Furtadiana de Desenvolvimento Econômico e a Ordem

Econômica Constitucional Brasileira. 2012. 232 f. Dissertação (Mestrado em Direito Econômico). Universidade de São Paulo, São Paulo, 2012.

LEFEBVRE, Henri. Marxismo. Porto Alegre/RS: L\&PM, 2009.

MARX, K. Contribuição à crítica da economia política. In: MARX, K., ENGELS, F. Obras Escolhidas. V1. 2a ed. Rio de Janeiro: Vitória. 1961.

MARX, K. Salário, preço e lucro. In: Manuscritos econômico-filosóficos e outrostextos escolhidos. São Paulo: Abril Cultural, 1978. 
SAWAYA, R. R. Inflação, Crescimento e Desenvolvimento: como a macroeconomia neoclássica impede o desenvolvimento. Rebela, Florianópolis/SC, v. 5, n. 2, p.225-254, maio/agosto 2015 .

SIEDENBERG, D.R. Dicionário do Desenvolvimento Regional. Santa Cruz: Edunisc, 2006.

SOLOW, Robert M.. A Contribution to the Theory of Economic Growth. The QuarterlyJournalOfEconomics, v. 70, n. 1, p.65-94, fev. 1956.

SOUZA, N. de J. de. Desenvolvimento econômico. 5. ed. rev. São Paulo, SP: Atlas, 2005. 